a systemic review and meta-analysis: Lancet 2008; 371(9614): 725-735. DOI: 10.1016/S01406736(08)60342-6

5. Quality Care Commission. The state of health care and adult social care in England. http://www. cqc.org.uk/sites/default/files/media/documents/ cqc_soc_report_2013_lores2.pdf laccessed 6 Feb 2014).

DOI: 10.3399/bjgp14X677419

\section{We need another word for 'chronic'}

Is it time to stop using the word 'chronic' and talking about chronic disease? The BJGP in December has the reference to chronic in the title of four of its articles. ${ }^{1-4}$ Language changes with time and with usage. For example, the phrase 'terminal care' has made a transition to the more positivesounding 'palliative care', not least because we are far more open in our discussions with patients than we were a generation or two ago and need to be sensitive to their interpretation of our terminology. Similarly, doctors may understand the term chronic in its primary dictionary sense of 'persisting for a long time or constantly recurring and so may the some of the public. ${ }^{5}$ But others are more likely to hear its secondary, informal meaning 'of a very poor quality' and be offended, frightened, or bemused by this label being attached to their disease or, worse still, to their general health?

As we revise our curriculum at Nottingham we hope to incorporate further student experience that is community based with patients who have single morbidity or multiple comorbidities. Our debate is not over the urgent need for such education with population demographics changing to an increasingly older population, but what we call it, rather than chronic disease. Could it be: long-term conditions; integration of care in complex disease; integrated care; managing complex conditions; communitybased disease; advanced primary care; living with long-term illness, or another new entity? Whatever term is adopted, it should be more optimistic and evolve from a discussion between disciplines and with patient participation groups.

Rodger C Charlton,

Professor of Primary Care Education, Division of Primary Care, University of Nottingham, UK.

E-mail: rodger.charltonanottingham.ac.uk

\section{REFERENCES}

1. Scherpbier-de Haan ND, Vervoort GMM, van Wee C, et al. Effect of shared care on blood pressure in patients with chronic kidney disease: a cluster randomised controlled trial. Br J Gen Pract 2013; DOI: 10.3399/bjgp13X675386

2. Seamark D, Seamark C, Greaves C, Blake S. GPs prescribing of strong opioid drugs for patients with chronic non-cancer pain: a qualitative study. $\mathrm{Br} J$ Gen Pract 2013; DOI: 10.3399/bjgp13X675403

3. Toye F, Seers K, Allcock N, et al. Patients' experiences of chronic non-malignant musculoskeletal pain-a qualitative systematic review. Br J Gen Pract 2013; DOI: 10.3399/ bjgp13X675412

4. Cornes 0 . Chronic fatigue syndrome: a patient's perspective. Br J Gen Pract 2013; DOI: 10.3399/ bjgp13X675458.

5. OED online Oxford University Press, 2014 http://oxforddictionaries.com/definition/english/ chronic?q=chronic (accessed 10 Feb 2014).

DOI: 10.3399/bjgp14X677428

\section{Primary care patients' reasons for choosing emergency department services in Jordan}

Over-use of emergency departments (EDs) by patients with primary care problems is a matter of concern. I studied patients and carers of children attending the family medicine clinics in the ED of Al-Bashir Hospital in Amman, Jordan' from May to July 2011, during office hours (Sunday to Thursday, 8:00-16:00) to determine their main reason for choosing this service rather than a GP or medical centre.

A total of 1310 patients attended: 747 (57\%) were adults, 563 (43\%) were children accompanied by carers and $778(59 \%)$ were female and 532 (41\%) male. Reasons for attending were: 374 (29\%) self-assessed urgency, 301 (23\%) convenience laccessible and less waiting time), 231 (18\%) selfassessed seriousness, 143 (11\%) took treatment but still not well, 122 (9\%) referred from other facilities, $97(7 \%)$ needed a second opinion, and 42 (3\%) were related to sick leave.

Siminski et al's survey in Australia ${ }^{2}$ suggested three important reasons: urgency, being able to see the doctor and have tests or X-rays done in the same place, and the seriousness or complexity of the health problem. ${ }^{1}$ The EMPATH study in the US ${ }^{3}$ identified five factors characterising patient's principal reasons for seeking ED care, with medical necessity the most frequent, followed by ED preference, convenience, affordability, and limitations of insurance.

There is an important distinction between clinically-assessed triage categories and self-assessed urgency and complexity. Patients can only be expected to act on their own judgement. ${ }^{2}$ Use of the ED is for most people an affirmative choice over other providers, rather than a last resort, and it is often a choice driven by lack of access or dissatisfaction with other providers. ${ }^{3}$

\section{Wafa Halasa,}

Senior Consultant Family Medicine, Ministry of Health, Amman, Jordan.

E-mail: wafahalasalahotmail.com

\section{REFERENCES}

1. Halasa W. Family medicine in the emergency department, Jordan. Br J Gen Pract 2013; 63(614): 462

2. Siminski P, Cragg S, Middleton R, et al. Primary care patients' views on why they present to emergency departments - inappropriate attendances or inappropriate policy? Aust J Prim Health 2005; 11(2): 87-96.

3. Ragin DF, Hwang U, Cydulka RK, et al. Reasons for using the emergency department: results of the EMPATH study. Acad Emerg Med 2005; 12(12): 1158-1166.

\section{Self management: what happens to people with long-term conditions in between NHS appointments?}

The NHS is grasping the nettle of activity promoting self-management as part of the long-term conditions (LTC) QIPP programme, but clinicians are slow to engage and consultations with individual patients are often few and far between. Is this really going to be enough to keep patients motivated to self-manage their condition? Less discussed, and even less understood is the role of voluntary and community organisations in promoting self-management. Organisations based in the community are well placed to engage, support, signpost and deliver activities to increase self-care, self-management, and levels of activation for people with LTCs.

The Think Ahead: Stroke Information Service in Wigan has developed a Self- 
Care for Stroke training programme for stroke survivors and carers. Working in partnership with local health, social care, and charitable organisations, weekly sessions are delivered in a relaxed informal and friendly environment over 6 weeks, and guest speakers talk about life after stroke, support for carers, communication, aids and adaptations, active living and healthy lifestyles, and goal setting. The course is endorsed by the UK Stroke Forum Education and Training, and has QISMET registration.

While community and voluntary organisations cannot take the place of clinical care when clinical care is needed, they can provide wide and varied support to people in their own communities. With the right support and encouragement from commissioners, health and social care professionals, community-based organisations really can be the genie in the bottle; give it a rub and see what happens. A wealth of local knowledge is available; good links and referral processes with other community organisations can truly empower people to self-manage and increase activation levels. Health and social care colleagues do not have all of the answers, time, or resources to truly do justice to increasing levels of activation in people with LTCs, nor to promote selfmanagement and self-care. However, working in partnership with community organisations can provide the synergy needed to develop and sustain changes to improve health outcomes. We just need to get on with the job.

\section{Fran Ryan,}

Project Manager, Think Ahead Stroke Information Centre, Ince, UK.

E-mail: frathink-ahead.org.uk

DOI: 10.3399/bjgp14X677446

\section{Improved support required to increase breastfeeding rates}

Rosie Sayers ${ }^{\prime 1}$ article is an interesting discussion on the impact of our wider culture on the acceptability of breastfeeding in public and suggests this as an important cause of low breastfeeding rates in the UK.

However, from my own personal and professional experience, I believe lack of effective support to overcome low confidence and common problems encountered when establishing breastfeeding (for example painful nipples and concerns about insufficient milk supplyl is at the core of the issue.

According to UNICEF, $81 \%$ of UK mothers in 2010 initiated breastfeeding demonstrating that women are generally motivated to breastfeed, however, by 6 weeks only $17 \%$ were exclusively breastfeeding. ${ }^{2}$ Increasingly mothers are discharged from hospital shortly after giving birth and usually before breastfeeding has become established. While mothers routinely have two to three follow-up home visits from midwives and health visitors, they report that these encounters are often rushed due to over-stretched resources with little continuity and that they commonly receive conflicting information. Women with breastfeeding difficulties are directed to drop-in clinics or seek information from organisations such as the National Childbirth Trust (NCT) or Le Leche League. This fragmentation of advice and followup can be overwhelming to new mothers and it is understandable why formula feeding is often seen as the most reliable option. A Cochrane review of breastfeeding support ${ }^{3}$ showed that, while all forms of extra support increased the length of time women continued to breastfeed, support that is only offered if women seek help themselves is unlikely to be effective, and suggested that predictable, scheduled, ongoing visits were key to extending the time that women breastfeed.

While the UK has made real progress in increasing rates of breastfeeding initiation, the focus of attention needs to shift to providing improved support to those mothers who want to continue doing so. In addition to the wider cultural factors highlighted in Rosie Sayers' article, focusing on issues including the nature, frequency, and continuity of long-term support as well as availability of effective information is central to tackling low breastfeeding rates in the UK.

\section{Laura D Garnham,}

Academic GP ST4 registrar, Imperial

College London, UK.

E-mail: l.garnhamaimperial.ac.uk

\section{REFERENCES}

1. Sayers R. Breast is best: just maybe in private? $\mathrm{Br} J$ Gen Pract 2014; 64(618): 44-45.

2. The Baby Friendly Initiative. UK breast feeding rates (UNICEF UK Baby Friendly Initiative, London) http://www.unicef.org.uk/BabyFriendly/ About-Baby-Friendly/Breastfeeding-in-the-UK/
UK-Breastfeeding-rates/ (accessed 6 Feb 2014).

3. Britton C, McCormick F, Renfrew M, et al. Support for breastfeeding mothers. Cochrane Database Syst Rev 2007; 1: CD001141.

DOI: 10.3399/bjgp14X677455

\section{Corrections}

In the September 2012 BJGP, the article by Shephard $E A$, et al. Clinical features of bladder cancer in primary care. Br J Gen Pract 2012; DOI: 10.3399/ bjgp12X654560, the authors reported PPVs for patients presenting with one attendance with haematuria. They regret this should have been the value for one OR MORE. In Figure 2 (the Risk Assessment Tool) all haematuria combinations increase by a factor of 1.62.0. In particular, haematuria in those aged $\geq 60$ years has a PPV of $3.9 \%(95 \% \mathrm{Cl}=3.5$ to 4.6$)$ as opposed to the published figure of $2.6(95 \% \mathrm{Cl}=2.2$ to 3.2$)$. In those aged $40-59$ years it is $3.1 \%(95 \% \mathrm{Cl}=1.0$ to 9.8$)$. The online version has been corrected.

\section{DOI: 10.3399/bjgp14X677464}

In the print February issue of the BJGP (pages 78-79), the article Moore $\mathrm{M}$, et al. Amoxicillin for acute lower respiratory tract infection in primary care: subgroup analysis of potential high-risk groups. Br J Gen Pract 2014; DOI: 10.3399/bjgp14X677121, the Results section was incorrectly published. We apologise for this error. This impacts significantly on the originally published article and only the online version of the article should be cited. Further to this, subsequent changes to the Results and Discussion sections were requested by the author and the corrected version is now available online. Correct Results for the print issue are as follows:

"Of the 2061 participants 595 (28\%) were aged $\geq 60$ years and $310(15 \%)$ had chronic lung disease lasthma or COPD). Groups were well balanced at baseline. Subgroup analysis for the three outcomes identified the following:

- No pre-specified subgroup was significantly more likely to benefit from antibiotic treatment in terms of symptoms rated moderately bad or worse. The result was of borderline significance for those with green sputum and there was modest impact on the median or interquartile range of symptom duration.

- Those with comorbidities llung disease, hear disease, diabetes, or prior hospital admission experienced a significantly greater reduction in symptom severity between days 2-4 (Interaction term $-0.28 P=0.003$; estimated effect of antibiotics $-0.28(95 \% \mathrm{Cl}=-0.44$ to -0.11$) P=0.001)$ (Table 1).

- No subgroup was significantly more likely to develop new or worsening symptoms.

An additional sentence has been added to the penultimate paragraph of the Discussion:

"There was some evidence of modest benefit in nonsmokers and those with shorter prior duration of illness although neither group was pre-specified."

The online version is correct and can be accessed at http://bjgp.org/content/64/619/e75.full

DOI: 10.3399/bjgp14X677473 